\title{
CRIAÇÃO DE PARQUES URBANOS EM ATERROS SANITÁRIOS DESATIVADOS, ESTUDO DO ATERRO SAPOPEMBA, SÃO PAULO, SP.
}

\author{
Andrea Volpe-Filik ${ }^{1}$, José Hamilton de Aguirre Junior ${ }^{2}$, Ana Maria Liner Pereira Lima ${ }^{3}$, Flávia
}

Bighetti Jorge Ferreira ${ }^{4}$, Mônica Salim ${ }^{5}$, Otávio Augusto Faria ${ }^{6}$, Ivan André Alvarez ${ }^{7}$

Os aterros sanitários constituem-se atualmente num grande problema social, ambiental e urbano devido à imobilização de grandes áreas nas cidades, produção de gases agravantes do efeito estufa, possível contaminação do solo e do lençol freático, além da possibilidade de invasões de sua área pela população de baixa renda, o que exige medidas constantes de monitoramento e intervenção das autoridades públicas (ATLAS AMBIENTAL DO MUNICÍPIO DE SÃO PAULO, 2004; PMSP, 2001; SILVA, 2001).

Estes locais necessitam de tratamento diferenciado ao de outras áreas degradadas, devido a fatores como a liberação de gás metano que representa um dos maiores limitantes para a implantação de vegetação (MATA E ANDRADE, 2000), dos riscos de explosão, do recalque diferencial do terreno (processo de acomodação após a decomposição da matéria orgânica), problemas de drenagem e compactação da camada superficial do solo utilizado no preenchimento do terreno (MATA E ANDRADE, 2000; SILVA, 2001).

Só na capital de São Paulo, existem atualmente 10 áreas de aterros desativados com potencial de recuperação através da criação de Parques Urbanos e abertura à população. Dentre eles, destaca-se o aterro desativado Sapopemba, localizado no bairro São Mateus, Zona Leste (PMSP, 2001; 2005).

O presente estudo levantou informações sobre características regionais onde o aterro Sapopemba está localizado, como clima, cobertura vegetal original e atual, relevo e geologia originais, histórico do bairro Sapopemba, indicadores sócio-econômicos da região e perfil ambiental e sócio-ambiental. Levantou-se, também, o histórico popular e a situação do aterro sanitário Sapopemba, por meio de entrevistas com os líderes e a comunidade local.

\footnotetext{
${ }^{1}$ Engenheira Agrônoma, Departamento de Produção Vegetal, ESALQ/USP, Piracicaba, SP, avfilik@esalq.usp.br

${ }^{2}$ Engenheiro Florestal, Departamento de Produção Vegetal, ESALQ/USP, Piracicaba, SP, jhaguirr@gmail.com

${ }^{3}$ Engenheira Agrônoma, Profa. Dra.Departamento de Produção Vegetal, ESALQ/USP, Piracicaba, SP, amlplima@esalq.usp.br

${ }^{4}$ Arquiteta, flaghuetti@yahoo.com.br

${ }^{5}$ Arquiteta, mosalvas@gmail.com

${ }^{6}$ Graduando em Eng. Agronômica, ESALQ/USP, otavio.faria@gmail.com

${ }^{7}$ Engenheiro Agrônomo, iaalvare@terra.com.br
} 


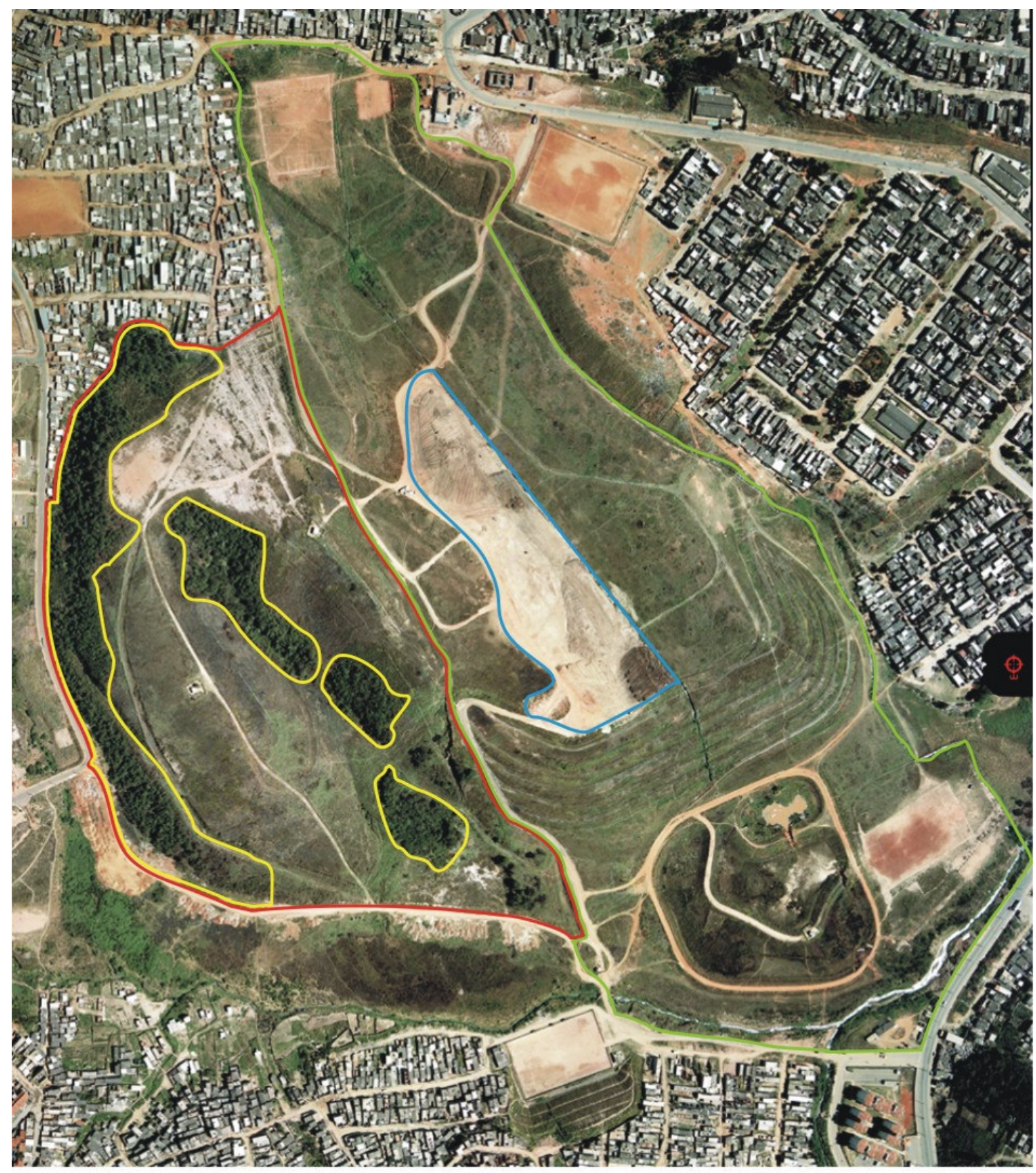

Área do Aterro

Área Lindeira com Mata

Área de Mata

Área das Mamoneiras

Figura 1 - Imagem de satélite do aterro Sapopemba - Fonte: Google Earth. 


\section{Localização}

O aterro desativado do Sapopemba localiza-se na região Sapopemba/São Mateus, Zona Leste de São Paulo, entre os seguintes extremos, nas coordenadas geográficas (Figura 1):

• 23o 37'15,31'S, 46o 27'14,73"O;

- 230 37'31,56"S, 46o 27'01,39"O;

- 23037 '43,281'S, 460 27'32,29"O;

• 230 37'31,13"S, 46o 27'28,70”O.

\section{Características Regionais (ATLAS AMBIENTAL DO MUNICÍPIO DE SÃO PAULO,} 2004)

\section{Clima}

O Clima ocorrente na região foi classificado, em duas categorias:

- Unidade Climática Natural: Clima Tropical Úmido de Altitude do Planalto Paulistano

- Unidade Climática Urbana: Unidade Climática Urbana Periférica da Zona Leste Residencial Baixo/Favelas-Sapopemba/São Mateus

\section{Cobertura vegetal original}

- Floresta Ombrófila Densa "Mata";

- Formações de várzea - campos (brejo)

\section{Cobertura vegetal atual}

A vegetação original encontra-se bastante alterada, passando por um processo constante de desmatamento. A área verde existente na região, sofreu redução, entre 1991 e 2000, de 38,25ha. A cobertura verde por habitante é de 2,32m2.

A vegetação ocorrente na área é de estágios iniciais de sucessão com alguns indivíduos de fases mais avançadas.

É marcante a presença de gramíneas e de espécies invasoras, a área é ocupada por construções que impedem a ocorrência de processos naturais de regeneração.

A região é classificada como de classe Urbano 1, que significa regiões com densa urbanização e escassez de vegetação, grande quantidade de prédios, vias pouco arborizadas e carência de praças e jardins públicos.

\section{Relevo e geologia originais}

A área do Bairro Sapopemba, possui em sua conformação original: 
- Embasamento pré-cambriano: unidades magmáticas e metamórficas (suítes graníticas indiferenciadas dos grupos São Roque do Itaberaba e complexo Embu).

- Sedimentos terciários da Bacia de São Paulo: conglomerados, areias, argilas e lamitos com espessuras variávies (métrica a decamétrica). Intercalações e interdigitações dos depósitos sedimentares das formações de Itaquaquecetuba, São Paulo, Tremembé e Resende.

- Pequena faixa: cobertura aluvial e colovial quaternária: Areias, argilas e conglomerados com espessura média.

- Complexo Embu: PCef- Filitos e subordinadamente sericita-xistos e micaxistos e Sedimentos Cenozóicos: TRd- Formação Resende - Sistema de leques associados à planície de rios entrelaçados. Lamitos, arenitos e conglomerados.

- É pequena a faixa PCeq- quartzitos, selimanita-muscovita, quartzitos e quartzitos feldspáticos.

\section{Zona Leste}

A região Leste Extremo da capital se caracteriza por grande concentração de usos residenciais de baixo padrão. Uma construção marcante na área é o Shopping Center Aricanduva e ocorre alguma ocupação por atividade industrial ao longo da Estrada do Pêssego, que encontra-se dispersa por toda a área.

\section{- Indicadores sócio-econômicos da região}

A região na qual está inserido o aterro Sapopemba possui densidade Populacional Bruta de 150 a 249,60 habitantes por hectare o que ocasiona uma pressão de degradação no ambiente.

Possui taxa de crescimento populacional anual negativa de $-6,24$ a $-0,01$. O perfil etário médio é de 23 a 25 anos e a renda média está entre $R \$ 1000,00$ e $R \$ 2000,00$.

A escolaridade média da região é de 6 a 7 anos.

A taxa de mortalidade infantil é de 15 a 20 a cada 1000 nascidos vivos.

A população favelada é de 5 a $10 \%$ do Total.

A taxa de mortalidade por causas externas está entre 80 e 100 por cada 100.000 habitantes.

Questões relativas à segurança encontram-se no dia-a-dia da população paulistana, principalmente em áreas em que isso é mais evidente.

Os índices de homicídios são a face mais conhecida da violência urbana. A probabilidade de mortes por causas externas ou não naturais, engloba acidentes de trânsito, suicídios, quedas, afogamentos, entre outras, além dos homicídios. 


\section{- Perfil ambiental e sócio-ambiental}

O perfil sócio-ambiental, obtido a partir da correlação entre o perfil ambiental e o socioeconômico, indica a região como entre os 7 distritos de São Paulo de pior classificação.

A divisão de classes de distribuição da vegetação no município de São Paulo, classifica a região do aterro Sapopemba como Urbano 1, ou seja, regiões com densa urbanização e escassez de vegetação. Ocorre grande quantidade de prédios, vias pouco arborizadas e carência de praças e jardins residenciais, possuindo valores de temperatura altos, acima de $30^{\circ} \mathrm{C}$.

\section{- Histórico do bairro Sapopemba}

O bairro Sapopemba, na zona leste, surgiu por volta dos anos de 1920, com a fixação de um grande número de portugueses, que se instalaram em grandes chácaras, dedicando-se ao plantio de hortifrutigranjeiros e de flores. Alguns anos depois, ergueram uma pequena igreja dedicada a Nossa Senhora de Fátima. Casas foram construídas ao redor da capela e um lento crescimento instalou-se na região.

Em 1957 foi erguido um santuário para a santa e, a partir dos anos 50, o desenvolvimento chegou e com ele um grande número de nordestinos, fugindo de mais uma terrível seca. Hoje o bairro possui uma população de 250.000 habitantes e convive com graves problemas como o da violência, o da falta de infra-estrutura e o da falta de lazer e de áreas verdes.

Sapopemba é uma palavra tupi-guarani que significa "raiz chata", ou seja, um tipo de raiz que se desenvolve juntamente com o tronco da árvore, chegando a $2 \mathrm{~m}$ de altura. No local existia uma grande árvore, provavelmente com o tipo de raiz característica (talvez figueira) que acabou por ser derrubada. Na literatura, também, podem ser encontradas 2 espécies com nome popular Sapopemba. No seu lugar, posteriormente, plantou-se uma paineira.

\section{Histórico e Situação Atual do Aterro Sanitário Sapopemba}

As informações obtidas foram levantadas a partir de entrevistas com os líderes e a comunidade local.

\section{Início de operação}

O aterro entrou em atividade entre os anos de 1979-1980, na gestão do Prefeito Reinaldo de Barros, sendo fechado em 1986. As atividades foram encerradas devido ao protesto da comunidade do entorno que exigiu seu fechamento. 


\section{Atividade do aterro}

Originalmente, a área tinha a conformação de fundo de vale. A deposição de lixo foi feita em camadas, atingindo um patamar de $70 \mathrm{~m}$ de altura, aproximadamente.

Durante o período de atividade, o aterro funcionou com a seguinte quantidade de resíduos dispostos descritos na Tabela 1.

Tabela 1 - Quantidade de resíduos sólidos dispostos no Aterro Sapopemba.

\begin{tabular}{|c|c|c|c|c|c|c|c|c|}
\hline Ano & $\mathbf{1 9 7 9}$ & $\mathbf{1 9 8 0}$ & $\mathbf{1 9 8 1}$ & $\mathbf{1 9 8 2}$ & $\mathbf{1 9 8 3}$ & $\mathbf{1 9 8 4}$ & $\mathbf{1 9 8 5}$ & $\mathbf{1 9 8 6}$ \\
\hline $\begin{array}{c}\text { Quantidade } \\
\text { (1000t/ano) }\end{array}$ & 82 & 751 & 664 & 598 & 531 & 101 & - & 384 \\
\hline
\end{tabular}

Fonte: PMSP/SSO/LIMPURB

Após a desativação, grandes quantidades de chorume foram liberadas através da decomposição do material orgânico ali depositado. Os queimadores funcionaram continuamente até recentemente.

\section{Ocupação da área}

A ocupação desordenada do entorno da área começou há cerca de 25 anos, na gestão de Paulo Maluf, e há um ano uma área bem próxima, ao aterro, ao longo do córrego, vem sendo invadida.

Nos anos de 1994-1995, na segunda gestão do Prefeito Paulo Maluf, o aterro seria transformado em usina de compostagem e também haveria a instalação de um incinerador, o que acabou não ocorrendo, devido novamente à pressão contrária da comunidade.

Em 2002, a comunidade se mobilizou novamente, realizando um abaixo-assinado para transformar o aterro em Área de Lazer/Centro Olímpico/Parque, havendo, desta forma, consenso que uniu forças para tentar viabilizar o objetivo.

\section{Importância local e regional}

O local é uma área que vem sendo utilizada pela população das mais diferentes maneiras.

Desde a utilização para o lazer e prática esportiva como acesso dos moradores dos diferentes bairros que a circundam. O que antes era uma formação vegetal contínua, hoje é uma área degradada, entre os fragmentos de mata vizinhos, ainda existentes. Os remanescentes florestais existentes são importantes fontes de informações da vegetação outrora existente na área.

\section{Características físicas atuais do aterro}


A área conta, atualmente, com pista de Cooper, algumas quadras para a prática de futebol, equipamentos de ginástica e caminhos feitos pelos moradores, além de guaritas e lagoas (utilizadas para captação de chorume durante a atividade do aterro).

\section{Vegetação existente no local do aterro Sapopemba}

A vegetação ocorrente na área caracteriza-se, principalmente, por vegetação herbácea (dominante) e arbustiva, sendo raros os elementos arbóreos que se restabeleceram no local.

\section{Área lindeira ao aterro Sapopemba}

Há uma área lindeira ao antigo Aterro Sapopemba, com alta densidade populacional, designada como Zona de Centralidade Polar SMZCPa/11 (zona de adensamento populacional pouco restritiva), destinada a este fim pela Subprefeitura de São Matheus. Esta área apresenta 4 fragmentos florestais num total de 3,78ha.

\section{CONSIDERAÇÕES FINAIS}

Áreas que dispõem de opções de lazer à população, como áreas verdes, com equipamentos esportivos e recreativos, principalmente em regiões carentes, permitem um incremento na qualidade de vida da comunidade local e dos arredores.

Estas áreas, além de importantes no contexto de áreas verdes municipais, com toda a complexidade de relações existentes no meio urbano, são fundamentais para a diminuição de problemas como a violência urbana. Diversos estudos demonstram este fato.

A área do antigo aterro Sapopemba possui a potencialidade de recuperação de uma área degradada, aliando sua recuperação ambiental à melhoria de qualidade de vida da população do entorno. Sua revegetação possibilitará o aumento da área verde disponível à população da região, e de efeitos microclimáticos locais benéficos.

Por se tratar de uma extensa área (38 ha) encravada em área totalmente ocupada por população, esta deve ser uma área prioritária para o poder público e de grande relevância por poder, após sua recuperação, formar um corredor verde, interligando o Morro do Cruzeiro, Sapopemba, Mauá e Baixada Santista.

\section{REFERÊNCIAS BIBLIOGRÁFICAS}

MATA E ANDRADE, J. C. Vegetação em aterros sanitários de resíduos sólidos urbanos: Estudo do caso do aterro sanitário Santo Amaro, São Paulo. Dissertação de Mestrado da Universidade do Estado do Rio de Janeiro, 2000. 186 p. 
Prefeitura Municipal de São Paulo. Análise, caracterização e proposta de ação para revitalização dos aterros desativados no Município de São Paulo. São Paulo, 2005. 57 p.

Prefeitura Municipal de São Paulo. Avaliação preliminar da viabilidade ambiental da implantação de Parques municipais em aterros sanitários desativados. São Paulo: Secretaria Municipal do meio ambiente, 2001. 74 p.

Secretaria Municipal do Verde e Meio Ambiente - SVMA. Atlas ambiental do município de São Paulo - $O$ verde, o território, o ser humano: diagnóstico e bases para a definição de políticas públicas para as áreas verdes no município de São Paulo. São Paulo, SP, Fundação Biblioteca Nacional, 2004, 266p.

SILVA, F.A.N. Avaliação ambiental preliminar de antigas áreas de disposição de resíduos sólidos urbanos do município de São Paulo. Dissertação de Mestrado do Instituto de Geociências - USP, 2001. 104p. 